\title{
Professores como intelectuais e a construção coletiva de conhecimentos didáticos
}

\author{
Caroline Pacievitch ${ }^{1}$ \\ Amanda Gabriela Rocha Oliveira ${ }^{2}$
}

\begin{abstract}
RESUMO
O objeto de estudo deste artigo é a formação continuada de professores de História a partir da produção coletiva de conhecimentos didáticos no Programa Institucional de Bolsa de Iniciação à Docência - Pibid História, com foco no processo de interlocução e produção coletiva desses conhecimentos envolvendo professores experientes e estudantes de licenciatura em formação. A problemática de fundo é como se aprende a ensinar História a partir da concepção de professores como intelectuais transformadores, conforme Henry Giroux. Os resultados auxiliam a demonstrar que o grupo de bolsistas de iniciação à docência e supervisores conseguiu realizar a construção coletiva de conhecimentos didáticos, além de explorar as relações entre perfil profissional e escolhas didáticas realizadas ao longo da pesquisa.
\end{abstract}

PALAVRAS-CHAVE: Formação de professores. Pibid. Conhecimentos didáticos. Intelectuais transformadores.

Teacher's as intellectuals and collective production of pedagogical content knowledge

\begin{abstract}
The object of this study is history teachers' education departing from the collective production of educational knowledge in the Institutional
\end{abstract}

\footnotetext{
${ }^{1}$ Doutora em Educação. Universidade Federal do Rio Grande do Sul, Porto Alegre, Rio Grande do Sul, Brasil. https://orcid.org/0000-0003-3484-8168. pacievitch@gmail.com.

${ }^{2}$ Graduada em História. Universidade Federal do Rio Grande do Sul, Porto Alegre, Rio Grande do Sul, Brasil. https://orcid.org/0000-0002-4565-6391.amandag.rocha@hotmail.com.
} 
Program of Teaching Initiation Scholarships - History (Pibid-História), in which the focus of the survey is the process of interlocution and collective production of these knowledge involving experienced teachers and undergraduate history students in training. The background problematic is how to learn history from the concept of teachers as transformative intellectuals, by Henry Giroux. The results allow to demonstrate that the group of teaching initiation scholars and supervisors teachers were able to make the collective construction of educational knowledge, and explore the relationship between professional profile and educational choices made during the survey period.

KEYWORDS: teacher's education. Pibid. Pedagogical content knowledge. Transformative intellectuals.

Profesores como intelectuales y la construcción colectiva de conocimientos didácticos

\section{RESUMEN}

El objeto de estudio de este artículo es la formación continua del profesorado de Historia a partir de la producción colectiva de conocimientos didácticos en el Programa Institucional de Bolsa de Iniciação à Docência - Pibid História, centrándose en el proceso de producción colectiva de esos conocimientos entre profesores expertos y futuros profesores en formación inicial. La problemática de la investigación es cómo se aprende a enseñar Historia a partir de la concepción de profesores como intelectuales transformadores, de acuerdo a Henry Giroux. Los resultados demuestran que el grupo de becarios de iniciación a la docencia y sus supervisores lograron construir conocimientos didácticos de forma colectiva, además de explorar las relaciones entre perfil profesional y tomadas de decisiones didáticas realizadas a lo largo de la investigación.

PALABRAS CLAVE: Formación de profesorado. Pibid. Conocimientos didácticos. Intelectuales transformadores 


\section{Introdução}

Este artigo é fruto de um projeto de pesquisa concluído em 2017, cujo objeto de estudo foi a formação continuada de professores de História a partir da produção coletiva de conhecimentos didáticos no subprojeto História do Programa Institucional de Bolsa de Iniciação à Docência (Pibid) de uma universidade federal brasileira. A problemática de fundo foi: como se aprende a ensinar História a partir da concepção de professores como intelectuais transformadores (GIROUX, 1997)?

Para possibilitar a exploração desse objeto de estudo, escolhemos como espaço de investigação um grupo de professores (chamados supervisores) e estudantes de graduação (chamados bolsistas de iniciação à docência - bolsistas ID) participantes do subprojeto Pibid História da universidade em questão. Pretendemos descrever, compreender e interpretar o potencial formativo da construção coletiva de conhecimentos didáticos e suas implicações na maneira como os formadores (professores universitários) conduzem o ensino da didática da História. O foco foio processo de interlocução e produção coletiva de conhecimentos didáticos envolvendo professores experientes (supervisores e coordenadores) e estudantes de licenciatura em formação (bolsistas ID).

Neste artigo, apresentamos os resultados gerais que auxiliam a demonstrar que tipos de conhecimento didáticoforam construídos no grupo e como essa construção teve a troca coletiva de experiências como fator diferencial. Além disso, exploramos as relações entre perfil profissional e escolhas didáticas realizadas ao longo do período, notando que, apesar das diferenças de idade e de formação, houve certa homogeneidade no que se refere às expectativas e aos referenciais teórico-metodológicos partilhados no coletivo.

A intenção teórico-metodológica da pesquisa foi desafiar a articulação entre a concepção de professor como ser pensante, que toma decisões e que de fato constrói a História ensinada nas escolas, e a necessidade de melhor 
entender como se pode operar na formação desses professores. Dentre os muitos caminhos possíveis, a escolha por trabalhar junto com os supervisores e bolsistas guiou a metodologia de investigação proposta, que pretende identificar-se como pesquisa na área de didática da História (BERGMAN, 1989/1990; CARDOSO, 2008; SANTISTEBAN; GONZÁLEZ; PAGÈS, 2010).

A pesquisa foi iniciada em maio de 2014 e concluída em fevereiro de 2017, limitada ao município de Porto Alegre. Cada escola participante do subprojeto História contou, no período, com um ou dois professores coordenadores (membros do Departamento de História e do Departamento de Ensino e Currículo da Universidade Federal do Rio Grande do Sul), um professor supervisor (lotado na escola) e outros professores que colaboraram eventualmente e grupos de quatro, seis ou oito alunos do curso de Licenciatura em História.

A primeira etapa do trabalho contou com diálogo entre colegas da área de Ensino de História da universidade, que já desenvolviam atividades com o Pibid, além de levantamento bibliográfico sobre o ensino de História na região. $\mathrm{Na}$ segunda, foram realizadas as entrevistas com professores supervisores, estudos teóricos, observação de sequências de aulas com e sem a participação de bolsistas ID e coleta de respostas a um questionário para delimitar o perfil dos bolsistas de iniciação à docência do projeto. Também foram coletados depoimentos de todos os bolsistas ID que tivessem vínculo com o subprojeto. Por fim, foram elaboradas análises globais finais, contando sempre com a leitura dos próprios supervisores e por leitores críticos externos.

A coleta de dados e as análises responderam aos interesses imediatos da pesquisa, isto é, oferecer interpretações sobre a formação continuada de professores de História na construção coletiva de conhecimentos didáticos. Os documentos obrigatórios produzidos foram: questionário de identificação geral dos supervisores e estudantes participantes, que informou dados básicos de sua trajetória de vida e formação; entrevistas gravadas com os 
supervisores, obedecendo aos princípios éticos sugeridos em Portelli (1997); observações de aulas/atividades realizadas pelos supervisores e pelos estudantes; questionário fechado de avaliação final do processo, respondido por todos os bolsistas ID e supervisores; diário de campo de umadas pesquisadoras, que também participava do subprojeto como coordenadora de área voluntária.

Esse conjunto de fontes foi analisado a partir de uma perspectiva qualitativa e participante e ofereceu a possibilidade de comparar as distintas intervenções, contribuindo para a reflexão sobre a construção de conhecimentos didáticos por parte dos supervisores.O projeto de pesquisa foi devidamente aprovado pela Comissão da Pesquisa da Faculdade de Educação e registrado na Plataforma Brasil ${ }^{3}$.

Os documentos gerados ao longo da investigação foram compreendidos como "documentos-monumento" (LE GOFF, 2003), pois seu valor reside no processo de construção coletiva de conhecimentos. $\mathrm{O}$ vínculo estreito entre pesquisa e ensino é característico de pesquisa em didática da História e, neste caso, é desejável porque os resultados devem contribuir para a própria prática como formadora. Sendo pesquisa participante, para realizar a crítica das fontes, foi importante a habilidade do "estranhamento" (GINZBURG, 2001), pois se esperava esclarecer aspectos da organização do trabalho pedagógico que pudessemorientar outros formadores em didática da História. Foram valorizados os detalhes, o que não estava óbvio, os desafios, as qualidades.

\section{Perfil dos bolsistas supervisores e de iniciação à docência participantes}

\footnotetext{
${ }^{3}$ O Comitê de Ética em Pesquisa (CEP) aprovou o projeto por meio do Parecer Consubstanciado n.742.124, de 17 de julho de 2014. A extensão do Projeto também foi submetida à apreciação e foi aprovada pelo Parecer Consubstanciado n.1.183.739, de 06 de agosto de 2015. O projeto de pesquisa e sua extensão também foram aprovados pela Comissão de Pesquisa da Faculdade de Educação da UFRGS, conforme registro de projeto de pesquisa n.27462 (pareceres de 09 de junho de 2014 e de 23/04/2015).
} 
Aplicamos o mesmo questionário para supervisores e bolsistas de iniciação à docência (ID). As perguntas giravam em torno da trajetória de vida pessoal e profissional, leituras e referências favoritas no mundo acadêmico, das artes e da política, participação em movimentos sociais, políticos, religiosos e culturais e expectativas sobre o Pibid. As respostas foram elaboradas de maneira descritivo-discursiva. Dos vinte e quatro bolsistas de iniciação à docência, vinte e um responderam ao questionário, bem como todos os quatro supervisores. Apresentamos, a seguir, alguns dados básicos sobre os bolsistas ID e sobre os supervisores separadamente, para melhor indicar o perfil. Em seguida, elementos como preferências teóricas e artísticas serão apresentadas em conjunto.

A técnica para a composição dosdados foi a contagem - anotação do conteúdo das respostas, questão por questão. Os números foram inseridos no editor de gráficos do Microsoft Word 2010, com o auxílio do Excel.A quase totalidade do grupo de bolsistas ID encontra-se na casa dos vinte anos, concentrando-se, a maioria (dezessete bolsistas), na faixa entre vinte e um e vinte e sete anos. Um bolsista preferiu não responder. Dezesseis bolsistas ID eram homens, e apenas cinco, mulheres. Tal divisão não corresponde ao que se nota nas turmas do curso de licenciatura em História, e tal fato foi objeto de discussão no grupo. Quase o mesmo número de bolsistas frequentou a escola privada, a escola pública e ambas as escolas.

Em relação à posição política, os bolsistas ID responderam de forma diversificada, porém praticamente todos se orientaram para uma visão de mundo baseada na necessidade de transformação social. Oito bolsistas ID indicaram ausência de religiosidade. Dois bolsistas apresentaram o cultivo de uma espiritualidade independente de religiões canônicas, e apenas dois bolsistas indicaram suas religiões: um deles, porém, não a especificou, citando apenas sua orientação geral (Paganismo), enquanto o outro indicou o Espiritismo. A grande maioria dos bolsistas ID não respondeu sobre filiação a partidos políticos, o que pode indicar tanto um desejo denão expor quanto a falta, efetivamente, de uma filiação. Apenas um bolsista indicou o seu 
partido político. Quanto à participação em movimentos sociais, as respostas apresentaram grande variedade, porém cada movimento citado apresenta apenas um participante. Os movimentos mencionados podem ser ligados à ideia de transformação social (feminismo, combate ao racismo, transporte público, acesso à universidade, questão estudantil, etc.). Nove bolsistas indicaram participação em movimentos sociais, doze não responderam.

Quanto aos supervisores, optou-se por apresentar seu perfil conjugando informações oferecidas nas entrevistas e no questionário fechado. Manteve-se a redação escrita pelos próprios professores quando se trataram de formulários escritos. Participaram professores em início, meio e final de carreira. Todos estudaram em escola pública e formaram-se em instituições públicas ou privadas, com nítido interesse pela formação continuada.

$\mathrm{O}$ vínculo com movimentos sindicais, políticos, artísticos, religiosos e culturais é um elemento importante para a constituição do ser docente. Assim, no Quadro 1, é possível perceber que há semelhanças na forma como esses professores atuam no espaço público fora da escola, o que os aproxima do perfil do bolsistas ID.

Quadro 1: Filiações

\begin{tabular}{|l|l|l|l|l|}
\hline & $\begin{array}{l}\text { Ana } \\
\text { Gabriel }\end{array}$ & Edson & Franciele & Larissa \\
\hline $\begin{array}{l}\text { Filiação } \\
\text { profissional }\end{array}$ & Andes e AHILA & Não & Sindicato \\
\hline $\begin{array}{l}\text { Filiação } \\
\text { partidária }\end{array}$ & $\begin{array}{l}\text { Não possuo vínculo com } \\
\text { partidos políticos. }\end{array}$ & Não & $\begin{array}{l}\text { Não milito } \\
\text { em partidos. }\end{array}$ \\
\hline $\begin{array}{l}\text { Posição } \\
\text { política }\end{array}$ & Esquerda & $\begin{array}{l}\text { Milito pela } \\
\text { transformação das } \\
\text { injustas condições } \\
\text { sociais presentes hoje, } \\
\text { em diferentes regiões. }\end{array}$ & $\begin{array}{l}\text { Esquerda } \\
\text { com algumas } \\
\text { contestações }\end{array}$ & Esquerda \\
\hline $\begin{array}{l}\text { Movimentos } \\
\text { sociais }\end{array}$ & $\begin{array}{l}\text { Jornadas } \\
\text { de Junho } \\
\text { de 2013 }\end{array}$ & $\begin{array}{l}\text { No Brasil tenho contato } \\
\text { mais direto com o MST } \\
\text { e o coletivo Utopia e } \\
\text { Luta. No México tenho } \\
\text { contato com as } \\
\text { comunidades de apoio }\end{array}$ & Não & $\begin{array}{l}\text { Bloco de d } \\
\text { Lutas Comissão de } \\
\text { Educação }\end{array}$ \\
\hline
\end{tabular}




\begin{tabular}{|c|c|c|c|c|}
\hline & & do EZLN. & & \\
\hline $\begin{array}{l}\text { Movimentos } \\
\text { religiosos }\end{array}$ & Não & $\begin{array}{l}\text { Não possuo } \\
\text { participação em } \\
\text { movimentos religiosos. }\end{array}$ & $\begin{array}{l}\text { Grupo de } \\
\text { Jovens }\end{array}$ & Não \\
\hline Religião & $\begin{array}{l}\text { Nenhuma } \\
\text { / Ateia }\end{array}$ & $\begin{array}{lr}\text { Acredito } & \text { que } \\
\text { desempenha } & \text { um } \\
\text { importante papel para } \\
\text { muitas sociedades e } \\
\text { indivíduos. }\end{array}$ & $\begin{array}{l}\text { Católica } \\
\text { apostólica } \\
\text { romana }\end{array}$ & Agnóstica \\
\hline $\begin{array}{l}\text { Movimentos } \\
\text { culturais }\end{array}$ & & $\begin{array}{lr}\text { Não } & \text { possuo } \\
\text { participação } & \text { em } \\
\text { movimentos } & \text { culturais } \\
\text { ou artísticos. } & \end{array}$ & Não & $\begin{array}{l}\text { Vários - } \\
\text { participação } \\
\text { em eventos - } \\
\text { mas como } \\
\text { público, não } \\
\text { que eu seja } \\
\text { protagonista. }\end{array}$ \\
\hline
\end{tabular}

Fonte: Projeto 'Formação de professores de História e a construção de conhecimentos didáticos' (20142015).

Assim como entre os bolsistas ID, opção política é pela esquerda, sempre com nuances, críticas e especificações. Isso não se reflete necessariamente em vínculo efetivo com partidos políticos específicos e por movimentos que contestem as injustiças sociais, notadamente ligadas à educação. Apenas dois declaram-se filiados a associações sindicais e nenhum opta por atuar em movimentos culturais. A participação em movimentos religiosos e a confissão de fé religiosa mostrou-se importante apenas para uma das docentes. Como visto, um perfil semelhante já se delineia entre os bolsistas ID.

Com relação às referências acadêmicas favoritas, a diversidade de nomes citados foi grande, tanto entre supervisores quanto entre bolsistas ID. Entre os mais citados, chamam a atenção os nomes de autores ligados ao marxismo e à esquerda, tais como Karl Marx, Eric Hobsbawm e E.P. Thompson. As referências acadêmicas identificadas não se restringem ao campo da História e passam por outros referenciais, de Weber a Foucault.As respostas quanto às referências na literatura ficcional, novamente, apresentam grande diversificação, mas com muitos pontos em comum entre supervisores e bolsistas ID. Destacam-se, entre os mais citados, autores que 
podem ser conectados com a crítica social, tais como Galeano, Márquez, Machado de Assis, Hemingway, Bukowski e Orwell.

As referências musicais apresentam ecletismo, indo de estilos como reggae até a música clássica. Entre os gêneros musicais e os artistas mais citados, podemos observar a presença tanto da música nacional quanto da internacional,desdemúsica popular até estilos musicais menos conhecidos. Os bolsistas ID e os supervisores responderam de maneira bastante variada sobre seus gostos cinematográficos. Sobre artes, destacam-se as menções à arte ligada ao engajamento político-social, mas é o tipo de manifestação artística menos indicado por todos.

A televisão é vista como meio de entretenimento: seriados, esportes, novelas, desenhos, etc. Chama atenção a menção aos meios de comunicação não vinculados à grande mídia. Alguns bolsistas citaram revistas que tratam de assuntos históricos e a presença tanto das mídias impressas quanto online, assim como grande variedade de usos da internet. $\mathrm{O}$ contato com a cultura contemporânea tem sido demonstrado, por diversos autores (ZAMBONI; DIAS; FINOCCHIO, 2014), como relevante para as transformações esperadas no ensino de História, principalmente do ponto de vista dos interesses dos estudantes. Até aqui, o cruzamento dos dados do perfil profissional, político e cultural dos supervisores e dos bolsistas ID demonstra coerência nas respostas, pois cada um apresenta o campo de interesse a partir do qual decidiu apresentar-se para esta investigação. $\mathrm{O}$ que se nota é uma apropriação crítica de elementos culturais que se refletem nas práticas de cada um e se mesclam com seus vínculos políticos e ideológicos. $\mathrm{O}$ contato com a cultura contemporânea se traduz nas práticas pedagógicas propostas na escola e, também, na concepção de mundo, de escola e de aluno que os professores reconstroem ao longo de sua vida profissional, como demonstraremos na próxima seção.

A análise desse perfil, conectada aos demais documentos que orientam esta investigação, proporciona bases para a compreensão do professor de História como um intelectual dotado de referências culturais 
próprias capazes de guiar o trabalho docente na sala de aula. Entretanto, a caracterização desse perfil só faz sentido - no escopo desta investigação - se cotejada com as produções realizadas no trabalho coletivo de supervisores e bolsistas ID.

\section{Planejamento, sala de aula e materiais didáticos}

Esta seção é resultado das análises dos relatórios anuais produzidos pelo subprojeto entre 2014 e 2016. Mesmo com uma coorte pequena, há diversidade de rotinas, materiais didáticos, usos de livro didático e recursos digitais nas aulas observadas e nos documentos em análise. Os materiais didáticos e as referências trazidas pelos docentes demonstram coerência com o perfil político, acadêmico e cultural apresentado na seção anterior. Os protocolos das observações de aulas, registrados no diário de campo e autorizados pelos participantes, foram organizados a partir de cinco temas: narrativa, material didático, conteúdo, teoria e interação na docência compartilhada. Esses cinco temas foram criados apenas para auxiliar no trabalho de análise, pois não se desconectam no trabalho de construção de conhecimentos didáticos. Assim, a descrição que segue procura contemplar estes eixos, mas não os aborda separadamente.

A primeira etapa das observações de aulas e atividades com o Pibid ocorreu entre outubro e dezembro de 2014, e a segunda etapa, entre abril de 2015 e julho de 2016. A previsão era coletar os depoimentos finais em julho de 2015, mas optou-se por fazer esta coleta ao final do primeiro semestre de 2016, a fim de estender a experiência com os professores.

O primeiro movimento que se destacou nas observações foi o seguinte: durante os meses de outubro a dezembro de 2014, foi necessário alternar observações de aulas ministradas exclusivamente pelo supervisor e voltar para a escola em outro dia para observar atividades desenvolvidas pelos bolsistas ID. Embora, nas entrevistas, todos os supervisores afirmassem 
trabalhar sempre em equipe, não foi possível notar relações diretas entre o planejamento cotidiano de cada professor e de seus bolsistas ID, principalmente no que se refere ao impacto da presença dos bolsistas ID perante a aprendizagem dos estudantes nas escolas. Por outro lado, as observações de 2015 mostraram outro cenário: mais entrosados, procuraram conectar as atividades cotidianas do supervisor com as intervenções dos bolsistas ID. Mesmo resguardadas as especificidades de cada tipo de aula (utilizando mais ou menos recursos, com maior ou menor participação dos supervisores), há relação direta entre as aulas ministradas pelos supervisores, as aulas ministradas pelos bolsistas ID e as rotinas dos estudantes de Ensino Fundamental ou Médio das turmas que participam do Pibid História.

Os quadros 2 e 3 sintetizam as principais características das aulas observadas em 2014 e em 2015, respectivamente.

Quadro 2: Sequências de aulas observadas em 2014

\begin{tabular}{|c|c|c|c|c|}
\hline & Ana Gabriel & Edson Antoni & Franciele & Larissa \\
\hline Tema & Guerra Fria & Guerra Fria & $\begin{array}{c}\text { Vinda da } \\
\text { Família Real } \\
\text { ao Brasil }\end{array}$ & $\begin{array}{c}\text { Ciclo do ouro no } \\
\text { Brasil }\end{array}$ \\
\hline Tipo de aula & $\begin{array}{c}\text { Expositiva } \\
\text { dialogada, } \\
\text { com atividade } \\
\text { de consulta } \\
\text { feita pelos } \\
\text { alunos. }\end{array}$ & $\begin{array}{c}\text { Expositiva } \\
\text { dialogada com } \\
\text { diapositivos, } \\
\text { seguida de } \\
\text { trabalho em } \\
\text { equipe - } \\
\text { produção de } \\
\text { jornal. }\end{array}$ & $\begin{array}{c}\text { Expositiva } \\
\text { dialogada com } \\
\text { diapositivos e } \\
\text { lousa }\end{array}$ & $\begin{array}{c}\text { Expositiva } \\
\text { dialogada com } \\
\text { lousa e livro } \\
\text { didático. } \\
\text { Perguntas e } \\
\text { respostas por } \\
\text { escrito. }\end{array}$ \\
\hline $\begin{array}{c}\text { Enquanto } \\
\text { isso, os } \\
\text { bolsistas ID }\end{array}$ & $\begin{array}{l}\text { Observam as } \\
\text { aulas. } \\
\text { Promovem } \\
\text { oficinas de } \\
\text { grafite e } \\
\text { saídas a } \\
\text { campo em } \\
\text { museus. }\end{array}$ & $\begin{array}{l}\text { Observam as } \\
\text { aulas. } \\
\text { Auxiliam nas } \\
\text { atividades } \\
\text { realizadas pelo } \\
\text { professor. } \\
\text { Promovem } \\
\text { oficinas e } \\
\text { saídas a campo. }\end{array}$ & $\begin{array}{l}\text { Observam as } \\
\text { aulas. } \\
\text { Desenvolvem } \\
\text { projeto } \\
\text { paralelo com } \\
\text { produção de } \\
\text { diário e zines. } \\
\text { Ministram } \\
\text { aulas em } \\
\text { turmas de } \\
\text { outros } \\
\text { docentes. }\end{array}$ & $\begin{array}{c}\text { Observam as } \\
\text { aulas. } \\
\text { Realizam } \\
\text { oficinas no } \\
\text { contraturno, } \\
\text { com turmas } \\
\text { diversas. }\end{array}$ \\
\hline
\end{tabular}




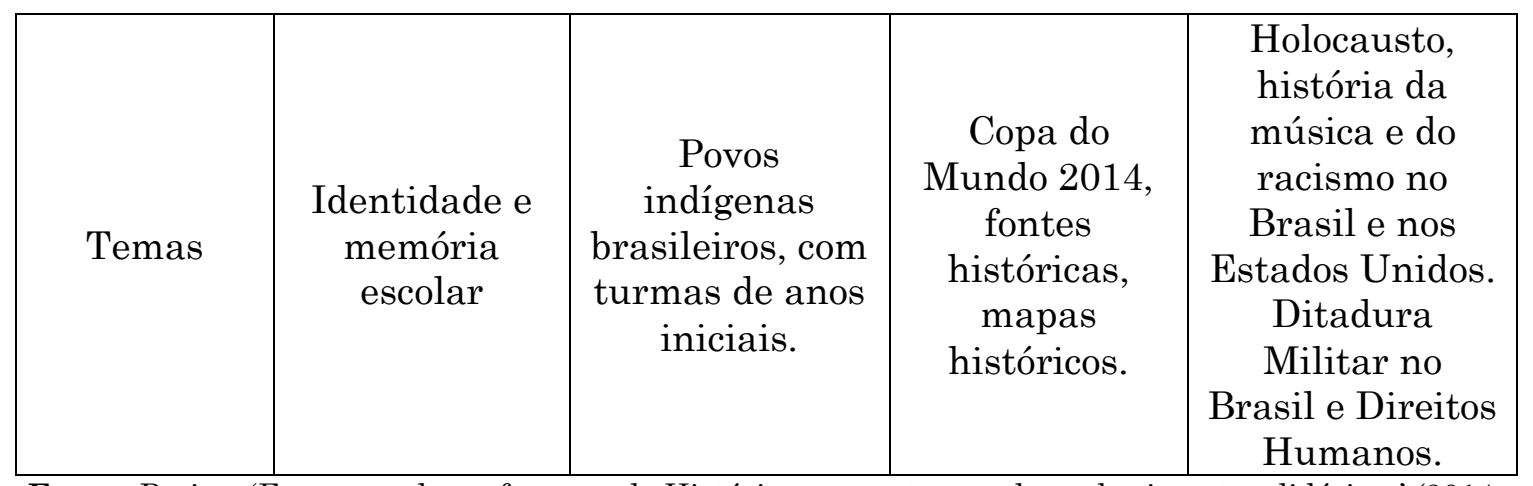

Fonte: Projeto ‘Formação de professores de História e a construção de conhecimentos didáticos' (20142015).

Quadro 3: Sequências de aulas observadas em 2015

\begin{tabular}{|c|c|c|c|c|}
\hline & Ana Gabriel & $\begin{array}{l}\text { Edson } \\
\text { Antoni }\end{array}$ & Franciele & Larissa \\
\hline Tema & $\begin{array}{l}\text { Nazismo, } \\
\text { Segunda } \\
\text { Guerra } \\
\text { Mundial e } \\
\text { Estados } \\
\text { Absolutistas }\end{array}$ & $\begin{array}{c}\text { Movimentos } \\
\text { sociais na } \\
\text { América } \\
\text { Latina }\end{array}$ & $\begin{array}{c}\text { Início da } \\
\text { conquista } \\
\text { europeia no } \\
\text { Brasil }\end{array}$ & $\begin{array}{c}\text { Primeira } \\
\text { Guerra Mundial }\end{array}$ \\
\hline Tipo de aula & $\begin{array}{l}\text { Jogo de } \\
\text { perguntas e } \\
\text { respostas. } \\
\text { Debate em } \\
\text { roda sobre o } \\
\text { filme "A } \\
\text { queda". }\end{array}$ & $\begin{array}{c}\text { Expositiva e } \\
\text { dialogada com } \\
\text { textos } \\
\text { impressos, } \\
\text { lousa e } \\
\text { imagens em } \\
\text { diapositivos. }\end{array}$ & $\begin{array}{c}\text { Expositiva } \\
\text { dialogada com } \\
\text { diapositivos, } \\
\text { lousa e livro } \\
\text { didático. }\end{array}$ & $\begin{array}{l}\text { Expositiva } \\
\text { dialogada com } \\
\text { lousa e livro } \\
\text { didático. } \\
\text { Perguntas e } \\
\text { respostas por } \\
\text { escrito. }\end{array}$ \\
\hline $\begin{array}{c}\text { Enquanto } \\
\text { isso, os } \\
\text { bolsistas ID }\end{array}$ & $\begin{array}{c}\text { Sugerem e } \\
\text { desenvolvem o } \\
\text { jogo, com } \\
\text { perguntas e } \\
\text { respostas. } \\
\text { Observam, } \\
\text { planejam e } \\
\text { realizam } \\
\text { outras aulas e } \\
\text { oficinas. }\end{array}$ & $\begin{array}{l}\text { Participaram } \\
\text { ativamente da } \\
\text { elaboração e } \\
\text { concretização } \\
\text { da nova } \\
\text { disciplina } \\
\text { proposta por } \\
\text { um grupo de } \\
\text { docentes na } \\
\text { escola. }\end{array}$ & $\begin{array}{c}\text { Planejam } \\
\text { aulas sobre o } \\
\text { mesmo tema } \\
\text { ensinado por } \\
\text { Franciele, } \\
\text { mas com } \\
\text { outras } \\
\text { abordagens } \\
\text { temporais e } \\
\text { metodológicas. }\end{array}$ & $\begin{array}{l}\text { Planejam aulas } \\
\text { sobre o mesmo } \\
\text { tema ensinado } \\
\text { por Larissa, } \\
\text { mas com outras } \\
\text { abordagens } \\
\text { metodológicas. }\end{array}$ \\
\hline Tema & $\begin{array}{c}\text { Mesmos temas } \\
\text { desenvolvidos } \\
\text { pela } \\
\text { professora. } \\
\text { Temas de } \\
\text { escolha dos } \\
\text { bolsistas ID } \\
\text { em oficinas e } \\
\text { outras }\end{array}$ & $\begin{array}{c}\text { Temas } \\
\text { desenvolvidos } \\
\text { na disciplina e } \\
\text { planejados em } \\
\text { conjunto. }\end{array}$ & $\begin{array}{c}\text { Mesmos } \\
\text { temas } \\
\text { desenvolvidos } \\
\text { pela } \\
\text { professora. } \\
\text { Temas de } \\
\text { escolha dos } \\
\text { bolsistas ID } \\
\text { em oficinas e }\end{array}$ & $\begin{array}{c}\text { Mesmos temas } \\
\text { desenvolvidos } \\
\text { pela professora. } \\
\text { Temas de } \\
\text { escolha dos } \\
\text { bolsistas ID em } \\
\text { oficinas e outras } \\
\text { atividades. }\end{array}$ \\
\hline
\end{tabular}


\begin{tabular}{|l|l|l|c|l|}
\hline & atividades ${ }^{4} \cdot$ & & $\begin{array}{c}\text { outras } \\
\text { atividades. }\end{array}$ & \\
\hline
\end{tabular}

Fonte: Projeto ‘Formação de professores de História e a construção de conhecimentos didáticos' (20142015).

As descrições construídas sobre as sequências de aulas observadas não serão expostas em detalhe neste artigo, mas são consideradas na interlocução com a análise dos materiais didáticos, exposta a seguir. É preciso ressaltar, mesmo assim, que não podem ser tomadas como exemplares ou generalizáveis do trabalho destes docentes, pois são sequências curtas dentro da totalidade de aulas que realizam ao longo do ano letivo. Tampouco se pretende avaliar ou julgar o desempenho docente. Trata-se de informações cruzadas com as entrevistas, com os questionários e com os demais documentos, para que se possa compreender melhor como o trabalho coletivo pode auxiliar na produção de conhecimentos didáticos por parte de docentes experientes.

A primeira constatação da pesquisa foi que o intervalo entre as observações de 2014 e 2015 demonstrou uma conexão maior entre as atividades realizadas individualmente pelos Supervisores e, depois, aquelas que foram realizadas junto com os bolsistas ID. As formas de trabalhar junto com os bolsistas foram diferentes em cada caso, mas foi possível notar que cada supervisor construiu - mesmo que provisoriamente - uma forma de se conectar com o trabalho dos bolsistas ID a partir da comunhão de seus interesses.

A busca de perceber a indissociabilidade entre teoria e prática e a produção do conhecimento na aula de História através da observação de aulas dos professores-supervisores do subprojeto História do Pibid e de aulas dos próprios bolsistas de História do Pibid proporcionou o questionamento da possibilidade de produção coletiva do conhecimento dentro do Pibid-História. Assim, outro objeto de análise forammateriais

\footnotetext{
4 Ao longo de 2015, professores e servidores das redes públicas municipal, federal e estadual realizaram greves. Em diversas escolas, este foi um tema debatido entre supervisores, bolsistas ID e estudantes, mesmo que não estivessem coordenados com o currículo e/ou os planejamentos estabelecidos.
} 
didáticos (livros, jogos, atividades, etc.) utilizado e/ou produzido pelo professor supervisor e/ou pelo bolsista ID. O objetivo da análise dos materiais didáticos foi perceber e teorizar sobre a indissociabilidade da reflexão e dos referenciais teóricos do docente de sua prática e didática dentro da sala de aula e como se poderia denominar ereconhecer esse fenômeno constante da produção intelectual dentro da profissão docente.

Optou-se por estudar os planejamentos materiais didáticos produzidos pelo Pibid História nos anos de 2014 a 2015 e que constam nos Relatórios de Atividades do subprojeto História enviados à Comissão de Acompanhamento do Pibid (CAP), que tem a função de, após análise, encaminhar os relatórios para a Capes.A partir de contagem simples, constatou-se que foram trinta planejamentos e quarenta materiais didáticos produzidos entre 2014 e 2015. Dentre os materiais didáticos,doze são diapositivos, sete são textos didáticos, outros sete são seleções de imagens e/ou documentos, quatro são exercícios, dois são fotos de oficinas e atividades realizadas, dois são questionários de diagnóstico aplicados aos alunos e, além disso, ainda há um mapa conceitual, um jogo de palavras cruzadas, um texto retirado da internet, uma foto dos materiais de uma das oficinas, um roteiro de estudos e um vídeo.

Há variedade de tipos de materiais didáticos, embora predominem os diapositivos, os textos didáticos e as seleções de imagens. É possível que outros tipos de materiais didáticos tenham sido veiculados nas aulas produzidas pelos bolsistas ID e pelos supervisores, mas que, por razões que escapam a esta pesquisa, não foram incluídos no relatório. Entretanto, mesmo parciais e incompletas, a construção de um panorama sobre os materiais didáticos a que se teve acesso permitirá acessar algumas características relevantes do encontro entre os bolsistas ID e os supervisores, na produção de atividades escolares para os estudantes ${ }^{5}$.

\footnotetext{
5 Importante salientar que nem todo material didático tem um planejamento correspondente, pelo menos não foi possível localizar no relatório. É possível que os planejamentos estivessem nos cadernos pessoais de cada docente supervisor e não tenham sido incluídos no relatório oficial.
} 
Quadro 4: Temas abordados nos planejamentos e materiais didáticos.

\begin{tabular}{|c|c|}
\hline Tema & Quantidade \\
\hline História do Brasil/Indígena/Afro-brasileira/ Africana & 14 \\
\hline História da América/ Indígena & 10 \\
\hline História da Europa/Contemporânea & 07 \\
\hline Outras (Política, Gênero e Comunicação) & 07 \\
\hline História do Brasil no Século XIX & 05 \\
\hline Ditaduras na América Latina & 04 \\
\hline Olimpíadas Nacionais de História do Brasil & 04 \\
\hline História Social / História Social do Futebol & 04 \\
\hline Guerra Fria & 03 \\
\hline História do Brasil no Século XX & 03 \\
\hline História Regional & 02 \\
\hline Segunda Guerra Mundial & 02 \\
\hline História da Ásia & 01 \\
\hline
\end{tabular}

Fonte: Projeto 'Formação de professores de História e a construção de conhecimentos didáticos' (20142015).

Em relação aos planejamentos, não há um modelo de organização único (tabela, texto, roteiro, cronograma, etc.), inclusive dentro da mesma equipe de trabalho (bolsistas supervisores e bolsistas ID da mesma escola). Ainda assim, é perceptível a reflexão teórico-metodológica nos planejamentos, principalmente em relação a questões sensíveis (como relações étnico-raciais e escravidão) e o conceito de história e de fontes históricas. Nota-se uma tendência de romper com o senso comum, como expressas nos seguintes trechos dos planejamentos.

Quadro 5: Reflexões teórico-metodológicas nos planejamentos

\begin{tabular}{|c|c|}
\hline $\begin{array}{c}\text { Reflexões teórico- } \\
\text { metodológicas }\end{array}$ & Exemplo \\
\hline Presença da História como & "O objetivo principal é aprofundar os ensinos \\
\hline
\end{tabular}




\begin{tabular}{|c|c|}
\hline $\begin{array}{l}\text { representação e do ensino de } \\
\text { História como algo para derrubar } \\
\text { o senso comum. Utilização do } \\
\text { cinema e das imagens como } \\
\text { recurso, e visão do recurso como } \\
\text { uma forma deilustrar. }\end{array}$ & $\begin{array}{l}\text { de Segunda Guerra Mundial, utilizando o } \\
\text { cinema como recurso. Os filmes serão o ponto } \\
\text { de partida para discussões, debates e } \\
\text { exposições sobre variados aspectos ou temas } \\
\text { contemplados pelo filme em questão, ou de } \\
\text { interesse dos alunos. Também possuem a } \\
\text { função de 'ilustrar' o conhecimento histórico, } \\
\text { ou em alguns casos, refutar o senso comum } \\
\text { que pode estar presente no imaginário do } \\
\text { aluno. Nesse sentido, um dos objetivos é } \\
\text { colocar o estudante diante da narrativa } \\
\text { fílmica, que fala sobre história e constrói } \\
\text { representações sobre opassado.” }\end{array}$ \\
\hline $\begin{array}{l}\text { Objetivo de romper com o senso } \\
\text { comum ao trabalhar com um } \\
\text { tema sensível e diversidade de } \\
\text { recursos e fontes apresentadas. }\end{array}$ & $\begin{array}{c}\text { "Considerando a inevitabilidade de opiniões } \\
\text { relacionadas ao conflito conhecido como } \\
\text { Guerra dos Farrapos, além de suas } \\
\text { consequências para a conformação de uma } \\
\text { suposta identidade gaúcha, não só na vida } \\
\text { escolar, mas em diversas esferas sociais, a } \\
\text { atividade se propõe a tratar de aspectos do } \\
\text { conflito e dos usos feitos desse episódio para } \\
\text { enobrecer e conformar uma identidade gaúcha. } \\
\text { Não temos um recorte temporal definido, mas } \\
\text { a ideia é apresentar como o conflito e seu } \\
\text { desfecho aparecem como discurso de } \\
\text { legitimação e enobrecimento do gaúcho.” }\end{array}$ \\
\hline $\begin{array}{l}\text { Conexão com a geografia próxima } \\
\text { à escola para trabalhar um tema } \\
\text { sensível. }\end{array}$ & $\begin{array}{l}\text { “A escola encontra-se em uma região limítrofe } \\
\text { entre bairros [...]. Esta região passou por } \\
\text { diversas mudanças ao longo do tempo, entre } \\
\text { elas um longo e gradual processo de remoção } \\
\text { da população pobre e predominantemente } \\
\text { negra para bairros distantes da cidade. Apesar } \\
\text { de tudo isso, ainda persistem locais onde os }\end{array}$ \\
\hline
\end{tabular}




\begin{tabular}{|c|c|}
\hline & $\begin{array}{c}\text { antigos moradores e/ou seus descendentes } \\
\text { permanecem vivendo, como o Quilombo [...]. A } \\
\text { região é conhecida por ser o berço do carnaval } \\
\text { na cidade, local de prática do futebol [...], de } \\
\text { resistência dos moradores contra a especulação } \\
\text { imobiliária e prática das religiões de matriz } \\
\text { africana.” }\end{array}$ \\
\hline $\begin{array}{l}\text { Intenção de ensinar como se } \\
\text { pensa historicamente, através de } \\
\text { questionamentos e do uso de } \\
\text { fontes diversas para trabalhar } \\
\text { com um tema sensível. }\end{array}$ & $\begin{array}{c}\text { “...] como sabemos o que ocorreu no passado? } \\
\text { Onde buscamos informações sobre ele? } \\
\text { Retiramos estas informações da imaginação? } \\
\text { Listar no quadro documentos possíveis de } \\
\text { adquirir informações [...]. Falar um pouco } \\
\text { sobre o trabalho do historiador e sua relação } \\
\text { com os documentos para a escrita da História. } \\
\text { É possível questionar sobre que tipo de } \\
\text { documentos podemos encontrar informações } \\
\text { sobre escravizados, e introduzir os nomes e } \\
\text { funções de cada documento presente no jogo.” }\end{array}$ \\
\hline
\end{tabular}

Fonte: Projeto 'Formação de professores de História e a construção de conhecimentos didáticos' (20142015).

O apelo a temas sensíveis pode ser teorizado como ensino através de questões socialmente vivas. Yannick Mével e Nicole Tutiaux-Guillon (2013) entendem que abrir as salas de aula a temas controversos é parte de um ensino que se preocupa com a formação para a cidadania e para o pensamento crítico. A riqueza dos materiais didáticos e as interrogações propostas nos planejamentos parecem indicar o desejo de compor domínio da historiografia e construção de estratégias didático-pedagógicas adequadas para romper com ideias preconcebidas por parte dos estudantes.

Percebe-se, também, que a maioria dos planejamentos se debruça sobre temas não tradicionais, isto é, conteúdos que não aparecem desenvolvidos nos livros didáticos e, quando aparecem, não é de uma forma aprofundada e constante (BRASIL, 2015). Apesar de estarem previstos no currículo do 
estado, nem sempre são trabalhados em aula, possivelmente porque demandariam uma maior dedicação de tempo do professor para realizar seu planejamento e execução e porque, com o Pibid, se torna um processo muito mais dinâmico e possível através do trabalho coletivo. Um exemplo disso é que, dos trinta planejamentos que abordam treze temáticas diferentes, seis são sobre História doBrasil/Indígena/Afro-brasileira/Africana e, somando com os planejamentos de outra temática muito próxima a esta, que é História da América/Indígena, equivalem a 1/3 do total de planejamentos. Tais dados podem demonstrar compromisso com a aplicação do Artigo 26-A da Lei de Diretrizes e Bases da Educação, que dizrespeito ao ensino de História e Cultura Africana, Afro-brasileira e Indígena, além do perfil político-ideológico e teórico-metodológico dos participantes, como visto na seção anterior.

Os diapositivos podem ser divididos de duas formas: de apresentação/explicação, relacionados à exposição de alguma atividade,e de problematização, no qual são desenvolvidos conceitos, eventos, imagens, questionamentos, etc. Nos do primeiro tipo, encontramos diapositivos como material de apoio (sobre a Olímpiada Nacional de História do Brasil, sobre linguagem e estruturados diferentes materiais informativos, sobre fontes históricas), que serviriam para orientar ou ajudar os alunos e alunas com uma atividade seguinte a ser desenvolvida. Nos materiais de segundo tipo há maior variedade de conceitos, eventos narrados e, principalmente, problematizações propostas nos materiais, sobre temas como imperialismo britânico, mapas históricos, machismo, feminismos, revolução e a independência do Haiti, Guerra Fria e Revolução Cubana, disputas ideológicas e a ascensão do Estado Novo.

Os textos didáticos seguem uma linha bastante parecida com a dos diapositivos. Alguns estão mais focados em transmitir ou fixar informações; outros são mais problematizadores. Os textos do primeiro tipo são normalmente associados a temáticas mais tradicionais, como a Revolução Francesa. São textos retirados de livros, artigos, páginas da internet ou 
outras fontes externas. As seleções de imagens e fontes históricas seguem o perfil de problematização e desconstrução de imagens e ideias tradicionais sobre as temáticas trabalhadas, por exemplo, em relação às imagens que reduzem o continente africano e o continente asiático a diversos estereótipos, fontes que permitam conhecer processos históricos importantes e normalmente colocados como secundários como a Declaração de Independência do Haiti.

É perceptível, nos planejamentos e, consequentemente, nos materiais, um alinhamento com a historiografia mais recente sobre os temas trabalhados, principalmente temas não tradicionais e sensíveis. Por exemplo, quando trabalhada a questão da escravidão no Brasil, a preocupação em promover uma identidade positiva e humanizada dos escravizados é algo constante, como exposto nesse planejamento:

A atividade busca aproximar-se da historiografia contemporânea sobre questões da escravidão no Brasil do século XIX, ao desmistificar o sujeito escravizado apenas como mão de obra sem vida além do trabalho. Através dos conceitos "trabalho", "família" e "moradia" busca-se encontrar uma aproximação com as relações sociais da época, onde, apesar dos negros estarem sujeitos como mão de obra escravizada, as relações não se limitavam a essa categoria. Planejamos a aula a partir desta aproximação com as diversas formas de convívio e resistência negra que permearam o país durante o recorte temporal estabelecido. [...].

Fonte: Projeto 'Formação de professores de História e a construção de conhecimentos didáticos' (20142015).

É difícil, entretanto, afirmar que há uma abordagem teóricometodológica constante e uniforme, tanto no campo da historiografia quanto no do ensino deHistória, nos planejamentos e materiais didáticos. Em alguns deles, nota-se a intenção de um protagonismo dos estudantes, 
enquanto outros são visivelmente focados na ação dos bolsistas ID em sala de aula.

É perceptível uma abordagem multicultural em diversos planejamentos, conforme argumentado por Guimarães e Silva (2007, p.55). Tal perspectiva é bastante presente nos planejamentos e materiais didáticos que trabalham com as temáticas de História e Cultura Africana, Afrobrasileira e Indígena, mas conteúdos tradicionais, como a conquista da América, também são trabalhados de uma forma nãotradicional, como se nota na redação do objetivo de um plano de aula sobre a conquista da América:

refletir sobre as diferentes formas de se pensar a diversidade de sociedades e culturas humanas; pensar a necessidade de se adotar um olhar antropológico no estudo da história de sociedades aparentemente muito diferentes da sociedade urbanocêntrica/urbanocentrada; discutir os conceitos de etnocentrismo e de civilização, além da ideia de abundância ou escassez de organizações sociais consideradas primitivas [...] considerando pré-julgamentos que enfatizam ausências em populações não-europeias. [...]

Fonte: Projeto 'Formação de professores de História e a construção de conhecimentos didáticos' (20142015).

Nesse planejamento, nota-se a questão da interdisciplinaridade, que se sustenta também em planejamentos sobre o Maio de 1968 francês (que fizeram parte de oficina interdisciplinar) e em trechos de livros como Facundo, de Sarmiento, usados para trabalhar a história argentina. Guimarães e Silva expõem que uma proposta curricular multicultural, crítica e transformadora depende, "entre outros fatores, de políticas de formação e profissionalização docente" (2007, p. 64). Aí é que se encontra o diferencial e o norteador dos planejamentos e materiais analisados, além da reflexão sobre sua contribuição para a formação inicial e continuada dos 
professores de História,que,emdiálogo e construção coletiva e constante de conhecimento dentro e fora de sala de aula são capazes de realizar uma proposta curricular crítica e transformadora.

\section{Considerações Finais}

Os argumentos de Giroux (1997) são pertinentes para questionara velha questão da relação entre prática e teoria na formação docente.É para evitar seguir na mesma pergunta que procuramos por indícios de construção coletiva de conhecimentos didáticos nessa pesquisa. Foi possível constatar que, além da diversidade de abordagens, a escolha dos temas demonstra o acolhimento de uma historiografia engajada e de um ensino comprometido com a inclusão, os direitos humanos e a educação antirracista, com práticas de ensino que não teriam se concretizado não fosse a adoção da produção coletiva de conhecimentos didáticos:

O papel do ensino não pode ser reduzido ao simples treinamento de habilidades práticas, mas que, em vez disso, envolve a educação de uma classe de intelectuais vital para o desenvolvimento de uma sociedade livre, então a categoria de intelectual torna-se uma maneira de unir a finalidade da educação de professores, escolarização pública e treinamento profissional aos próprios princípios necessários para o desenvolvimento de uma ordem e sociedade democráticas. (GIROUX, 1997, p. 162)

Em um momento em que se percebe a fragilidade da democracia e as constantes ameaças à educação de modo geral e, principalmente, à educação pública no Brasil, defendemos o uso do conceito de intelectual para designar aqueles que exercem a profissão docente para radicalizar a afirmação de que toda decisão pedagógica é também uma decisão política. Ao que tudo indica, as construções coletivas realizadas no Pibid-História 2014-2016 proporcionaram uma experiência de formação docente que permitiu (dentro 
de limites que não puderam ser mapeados pelas fontes documentais utilizadas) a formação dos bolsistas supervisores e ID como intelectuais transformadores.

Fica evidente, na conjugação entre as narrativas dos supervisores e as observações de aulas, que houve a tentativa de construir conhecimentos que atendessem às necessidades dos estudantes, que contassem com métodos inovadores de ensino e que respeitassem as matrizes historiográficas das quais, em essência, compartilham, apesar das diferenças entre períodos e instituições de formação. Pode-se arriscar que os conhecimentos produzidos por bolsistas supervisores e ID, junto com os coordenadores de área, configuram-se como histórico-didáticos, tal como delineamos em outra ocasião (PACIEVITCH, 2017).

Construir conhecimentos histórico-didáticos significou, para esse grupo, projetar, vivenciar e avaliar o ensinar e o aprender História, na confluência de distintas experiências com os estudantes da educação básica. As compreensões expressas pelo grupo vão ao encontro das seguintes ideias, que consideramos potentes para as reflexões da didática da História: ensinar e aprender História é mostrar possibilidades, transmitir conhecimentos e valorizar o estudante, aprender sobre si ao mesmo tempo que se ensina com os jovens. Em articulação com a compreensão de didática, trata-se de transformar o conhecimento de forma que atinja os estudantes, jogando com linguagens distintas e compreensíveis, que mostrem caminhos para os estudantes e que os ajudem a lidar com os valores e com as consequências de questões candentes para a formação cidadã.

\section{Referências}

BERGMAN, Klaus. A história na reflexão didática. Revista Brasileira de História, São Paulo, v.9, n.19, p. 29-42, set. 1989/fev. 1990.

CARDOSO, Oldimar. Para uma definição de didática da história. Revista Brasileira de História, São Paulo, v.28, n.55, p.153-170, 2008. 
GINZBURG, Carlo. Olhos de madeira: nove reflexões sobre a distância. São Paulo: Companhia das Letras, 2001.

GIROUX, Henry. Os professores como intelectuais: rumo a uma pedagogia crítica da aprendizagem. Porto Alegre: Artes Médicas, 1997.

LE GOFF, Jacques. História e Memória. Campinas: Editora da Unicamp, 2003.

MÉVEL, Yannick; TUTIAUX-GUILLON, Nicole. Didactique et Enseignement de l'Historie-géographie au Collège et au Lycée. Paris: Publibook, 2013.

PACIEVITCH, Caroline. Conhecimento didático e formação de professores de História: contribuições para a teoria e a prática. Diálogo Andino. Arica, n.53, p. 117-126, jun. 2017. Disponível em: <https://scielo.conicyt.cl/pdf/rda/n53/0719-2681rda-53-00117.pdf>. Acesso em: 19 nov. 2019.

PORTELLI, Alessandro. Tentando aprender um pouquinho, algumas reflexões sobre ética na história oral. Projeto História, São Paulo, n.15, abr. 1997.

SANTISTEBAN, Antoni; GONZÁLEZ, Neus; PAGÈS, Joan. Una investigación sobre la formación Del pensamiento histórico. In: ÁVILA, R.M.; RIVERO, M.P. \& DOMÍNGUEZ, P.L. Metodología de investigación en ciências sociales. Zaragoza: Institución "Fernando el Católico", 2010, p.115-128.

SILVA, Marcos; GUIMARÃES, Selva. Ensinar História no século XXI: em busca do tempo entendido. Campinas, SP: Papirus, 2007.

ZAMBONI, Ernesta; DIAS, Maria de Fátima; FINOCCHIO, Silvia. Peabiru: um caminho, muitas trilhas. Ensino de história e cultura contemporânea. Florianópolis: Letras Contemporâneas, 2014.

Recebido em setembro de 2018.

Aprovado em julho de 2019. 